\title{
O DIREITO À QUALIDADE DA/NA EDUCAÇÃO INFANTIL: ENTRE A MAXIMIZAÇÃO DO DIREITO E AS INTENCIONALIDADES DO PRIVADO
}

\author{
THE RIGHT TO THE QUALITY OF/IN EARLY CHILDHOOD EDUCATION: \\ BETWEEN THE MAXIMIZATION OF RIGHT AND INTENTIONALITIES OF \\ PRIVATE ONE
}

\begin{abstract}
Camila Maria Bortot Doutoranda em Educação na Universidade Federal do Paraná (UFPR) Mestra em Educação pela Universidade Estadual de Maringá (UEM) Bolsista da Coordenação de Aperfeiçoamento de Pessoal de Nível Superior. Curitiba, Paraná - Brasil camilabortot@gmail.com
\end{abstract}

Elisângela Alves da Silva Scaff Pós-Doutora e Doutora em Educação pela Universidade de São Paulo (USP). Professora associada do Departamento de Planejamento e Administração Escolar e do Programa de Pós-Graduação em Educação da Universidade Federal do Paraná.

Curitiba, Paraná - Brasil elisscaff@gmail.com

\begin{abstract}
Resumo: O presente texto objetiva identificar e compreender a concepção de qualidade da Educação Infantil que se apresenta em documentos que orientam a privatização desse nível de ensino. Por meio de um estudo bibliográfico e documental, o artigo se orienta pela seguinte questão de pesquisa: Quais os fundamentos e implicações da privatização sobre a qualidade da Educação Infantil? Apresentamos a qualidade como princípio do direito à Educação Infantil e seu detalhamento nas bases legais. Nesse contexto, as orientações emanadas da Nova Gestão Pública se destacam e as relações com o terceiro setor se aprofundam. Na Educação Infantil, duas instituições fundacionais são protagonistas na produção teórica sobre qualidade e orientação a processos de privatização nesse nível de ensino: Fundação Maria Cecília Souto Vidigal e Fundação Itaú Social. Em razão desse protagonismo tomamos para análise o documento Educação Infantil em debate: a experiência de Portugal e a realidade brasileira, de 2014, por elas promovido, no qual verificamos enunciados voltados à implementação de parcerias público-privadas e de oferta de políticas sociais focalizadas, utilizando o modelo português como referência, contrapondo-se a toda discussão sobre qualidade na Educação Infantil, em especial a de crianças de zero a três anos. Concluímos que as intencionalidades propaladas não convergem com as preocupações sobre a qualidade do atendimento educativo que será oferecido nem com o nível de formação dos que estiverem envolvidos em sua consecução, muito menos com as características específicas do contexto brasileiro.
\end{abstract}

Palavras-chave: Direito à Educação Infantil. Políticas Educacionais. Público e Privado. Qualidade.

\begin{abstract}
The present text aims to identify and understand the quality concept in Early Childhood Education presented in documents that guide the privatization of this education level. Through a bibliographical and documental study, the article is guided by the following research question: what are the fundamentals and implications about the quality of Early Childhood Education between the public and private? We present quality as a principle of the right to childhood education and how it has been detailed by legal bases. In this context, the New Public Management stands out and the dialogue with the third sector intensifies, strongly represented by Todos pela Educação Movement. In Early Childhood Education, two foundations are protagonist: Maria Cecília Souto Vidigal Foundation and Itaú Social Foundation. The data produced by foundations, related to quality, direct us to analyze the document "Early Childhood Education in debate: the Portugal experience and Brazilian reality" (2014). We verify that what is presented are guidelines for the implementation of public-private partnerships to provide focused social policies, using the Portuguese model as a reference to Brazilian Early Childhood Education, opposing all discussions about quality concept, especially for children from zero to three years old. We concluded that the intended intentions do not converge to the concern with the quality of the educational service that will be offered, nor with the level of training of those who are involved in its achievement, much less with the specific characteristics of the Brazilian context.
\end{abstract}

Keywords: Right to Early Childhood Education. Educational Policies. Public and Private. Quality.

\section{Para citar - (ABNT NBR 6023:2018)}

BORTOT, Camila Maria; SCAFF, Elisângela Alves da Silva. O direito à qualidade da/na Educação Infantil: entre a maximização do direito e as intencionalidades do privado. Eccos - Revista Cientifica, São Paulo, n. 52, p. 1-18, e13269, jan./mar. 2020. Disponível em: https://doi.org/10.5585/eccos.n52.13269. 


\section{Introdução}

A Educação Infantil no Brasil, de zero a cinco anos, é uma etapa que tem como princípio o direito público subjetivo ${ }^{1}$ ao acesso, permanência e qualidade das instituições de ensino consignado na Constituição Federal (CF) de 1988, que reconhece sua oferta como dever do Estado (art. 208, IV) e propugna seu atendimento em creches e pré-escolas. A etapa é inscrita no art. $4^{\circ}$, II, da Lei de Diretrizes e Bases da Educação Nacional (LDB, Lei nº 9.394/1996), considerada a primeira etapa da educação, visando o desenvolvimento integral das crianças. Sobre o direito à Educação Infantil, Pinto (2007) afirma que ele foi incorporado tardiamente na legislação brasileira, dado que o artigo 205 da Carta Magna de 1988 define que a educação é dever do Estado e também da família, e o inciso IV do art. 208, alterado pela Emenda Constitucional (EC) n. 53, de 2006, detalha que o Estado deve garantir creche e pré-escola às crianças até 5 anos de idade, "[...] podendo os primeiros demandá-lo judicialmente para garantir o cumprimento do que estatui a Lei Maior.” (op.cit., p. 121)

Ao final do século XX, adquiriu vulto o debate sobre a qualidade da educação, no âmbito das reformas gerenciais implantadas sob o argumento da eficiência e da eficácia educacional. Tais reformas, pautadas nas mudanças dos processos produtivos industriais e pela adoção, inicialmente na esfera privada e em seguida na pública, da gestão por resultados e, principalmente, da concepção de gestão para a qualidade total, propugnam novos padrões de sociabilidade que envolvem desde coletivos sociais a organizações e fundações ligadas ao terceiro setor, na busca da Nova Gestão Pública (NGP) (PERONI; OLIVEIRA; FERNANDES, 2009). Esses novos padrões atingem diretamente a Educação Infantil, precipuamente pela influência das organizações do terceiro setor na elaboração de políticas educacionais para o atendimento de zero a cinco anos no Brasil, o que demonstra uma retirada, mesmo que parcial, do Estado e sua desresponsabilização do Estado.

A dicotomia entre público e privado no âmbito da Educação Infantil voltou a se acirrar após a implementação nacional, em 2007, do Fundo de Manutenção e Desenvolvimento da Educação Básica e de Valorização dos Profissionais da Educação (FUNDEB), que autoriza a contabilização de matrículas e o repasse de recursos públicos para instituições de Educação Infantil comunitárias, filantrópicas e confessionais privadas, ainda que sem finalidades lucrativas. Ligados a esses arranjos, esses grupos têm se tornado produtores de conhecimento para essa etapa da educação e incidido sobre os rumos das políticas educacionais, como constata Krawczyk (2009, p. 24) ao afirmar que “[...] o setor empresarial está ocupando, de forma cada vez mais enfática, o espaço da construção de um projeto político educacional para o País, 
inclusive sendo reconhecido como o ator imprescindível nesse processo." Por consequência, indagamos: Quais os fundamentos e implicações da privatização sobre a qualidade da Educação Infantil?

Para responder a esse questionamento, o presente texto busca identificar e compreender a concepção de qualidade da Educação Infantil que se apresenta em documentos que orientam a privatização desse nível de ensino. A pesquisa foi desenvolvida por meio de um estudo bibliográfico e documental, estruturado em dois momentos: primeiramente, apresentamos a qualidade como princípio do Direito à Educação Infantil e como ela vem sendo detalhada pelos textos legais; em seguida, examinamos encaminhamentos e proposições para a efetivação da qualidade de duas fundações propositoras de políticas e conhecimento para o campo da Educação Infantil - Fundação Maria Cecília Souto Vidigal (FMCSV) e Fundação Itaú Social -, como representação empírica da ótica do setor privado sobre esse nível educacional, tomando como referência o documento por elas promovido: Educação Infantil em debate: a experiência de Portugal e a realidade brasileira (2014); ao fim, tecemos as considerações finais que sintetizam respostas à questão proposta neste texto.

\section{Qualidade como princípio do direito à educação das crianças pequenas}

O debate sobre a qualidade vem se acirrando desde 1990, em conjunto com as reformas gerenciais ligadas aos conceitos de eficiência e eficácia no Brasil. Gentili e Silva (2005) asseveram que, influenciada pelas mudanças dos processos produtivos, uma determinada concepção de qualidade constituiu importante fator de impacto no processo de elaboração e avaliação de políticas educacionais, adotada que foi, inicialmente, na esfera privada, e em seguida na pública, da gestão por resultados e, principalmente, da concepção de gestão para a qualidade total.

Tais implicações para as políticas educacionais brasileiras remontam ao plano de ações organizado pelo Ministério da Administração e da Reforma do Estado (MARE), na década de 1990, que expressou as mediações da reorganização da ordem mundial, marcada por intenso processo de globalização, reorientando a economia e, por conseguinte, as políticas públicas na perspectiva do gerencialismo. A proposta de reforma do Estado brasileiro teve como referência a Nova Gestão Pública, pela qual o exercício da governança é entendido na perspectiva do cumprimento de metas de desempenho e especificação de padrões e indicadores de qualidade, bem como o incentivo às parcerias público-privadas em educação. (ADRIÃO, et. al., 2015) 
A qualidade é um termo amplo e polissêmico, construído socialmente, que considera o ambiente histórico e cultural no qual se insere, e, enquanto princípio, deve ser utilizado em sua perspectiva maximizadora:

Podemos então concluir que a adoção de perspectiva maximizadora sobre o princípio
da qualidade do ensino significa não excluir previamente essa dimensão do âmbito de
proteção imediato do direito à educação - normalmente identificado à luta por acesso
- , e não limitar o conteúdo jurídico desse princípio a aspectos considerados mínimos
ou a apenas algumas de suas dimensões, escolhidas por razões de pragmatismo técnico
ou governamental, por interesse de atores privados ou apoiadas no mero senso
comum. (XIMENES, 2014a, p. 1038)

Atrelado a essa perspectiva maximizadora do direito à educação de qualidade, Ximenes (2014b) estabeleceu sete dimensões de parâmetros que devem ser considerados na construção/definição da qualidade, referidas: aos estudantes, ao ambiente escolar, às condições de infraestrutura e insumos básicos, aos conteúdos, aos processos educacionais, aos resultados e ao financiamento público. O autor destaca a importância da "estruturação de um sistema amplo de indicadores de realização, que venha a substituir os enfoques reducionistas que sobrevalorizam resultados padronizados em detrimento da maior parte dos demais elementos." (XIMENES, 2014b, p. 402)

Na Educação Básica, de acordo com os diferentes contextos e períodos da história, qualidade foi entendida de diversas maneiras. Nas últimas três décadas, considerando a oferta limitada de vagas, a preocupação esteve voltada para a expansão das redes de ensino; o processo de expansão das matrículas e o alto índice de retenção dos alunos levou à identificação do termo qualidade com progressão no sistema - assim, a educação de qualidade deveria garantir não apenas o acesso, mas o prosseguimento nos estudos. A garantia de acesso e permanência dos estudantes evidenciou um novo desafio, pelo qual a noção de qualidade passou a ser associada ao sucesso escolar, mensurado por meio de testes e avaliações (OLIVEIRA; ARAÚJO, 2005; CURY, 2006). Segundo Tomasevski (2001) e Ximenes (2014b), existem quatro dimensões necessárias ao direito à educação de qualidade, derivadas das obrigações do direito internacional: disponibilidade, acessibilidade, aceitabilidade e adaptabilidade. O Quadro 1, sintetiza seus principais elementos. 
Quadro 1 - Quatro dimensões necessárias ao direito à educação de qualidade

\begin{tabular}{|l|l|l|}
\hline \multicolumn{1}{|c|}{ Dimensão } & \multicolumn{3}{|c|}{ Características } \\
\hline Disponibilidade & $\begin{array}{l}\text { Oferta por meio de instituições educacionais; programas de educação em } \\
\text { quantidade suficiente no âmbito do Estado; condições físicas e } \\
\text { pedagógicas; }\end{array}$ \\
\hline Acessibilidade & $\begin{array}{l}\text { Acessível a todos: não discriminação, acessibilidade física e } \\
\text { acessibilidade econômica. }\end{array}$ \\
\hline Aceitabilidade & Forma e o conteúdo, currículos e os métodos pedagógicos. \\
\hline Adaptabilidade & $\begin{array}{l}\text { Flexibilidade em adaptar-se às necessidades de sociedades e comunidades } \\
\text { em transformação e para responder às necessidades dos estudantes dentro } \\
\text { da diversidade de seus contextos sociais e culturais. }\end{array}$ \\
\hline
\end{tabular}

Fonte: Tomasevski (2001) e Ximenes (2014b). Adaptado pelas autoras.

Na visão das autoras, as quatro dimensões compõem o direito à educação de qualidade, cada uma com sua especificidade, mas que, integradas, são fundamentais. A máxima realização do direito à educação de qualidade depende de sua concepção ampla e adaptável, cujo acesso é componente fundamental, mas não suficiente, para a caracterização ampla da qualidade.

Como dever do Estado, a garantia da educação, positivada no Artigo 208 da CF de 1988, define a regra de oferta da Educação Infantil em creche e pré-escolas às crianças até cinco anos de idade, e no Artigo 206 normatiza os princípios do ensino, que integram as condições para um ensino de qualidade. Essa oferta, portanto, precisa ter como base padrões de qualidade, uma vez que esse é um princípio norteador do ensino, conforme observado no inciso VII (BRASIL, 1988). A partir disso, apresentamos alguns marcos legais que orientam e organizam a qualidade e seus desdobramentos/encaminhamentos.

Em linhas gerais, ao estabelecer a Educação Infantil como direito das crianças por ser um direito subjetivo (art. 208, VII, § $1^{\circ}, \mathrm{CF} / 1988$ ) e primeira etapa da educação (art. 29, LDB/1996), a Constituição Federal de 1988 incorporou ao sistema de ensino as creches e préescolas, estabelecendo como dever do Estado e como competência dos municípios o atendimento, com qualidade, das crianças na faixa etária de zero a cinco anos de idade, em colaboração com os estados e a União. Com a EC no 59/2009, estabeleceu a gratuidade e a obrigatoriedade do atendimento a partir dos quatros anos de idade e as regras para a distribuição de recursos para todas as etapas da Educação Básica, dentre elas a Educação Infantil. (BRASIL, 2009)

A LDB, Lei nº 9.394 de 1996, integrou a Educação Infantil à Educação Básica. Com as alterações sancionadas pela Lei $\mathrm{n}^{\circ} 12.796$ de 2013, a educação básica, gratuita e obrigatória passa a contemplar a faixa etária dos 4 aos 17 anos de idade, cujo atendimento será realizado em creches para as crianças de zero a três anos e pré-escola às de quatro e cinco anos. A referida 
lei, além de reiterar a gratuidade da Educação Infantil, de zero até os cinco anos de idade, estabelece regras comuns para a organização da etapa, como avaliação, atendimento regular e especializado, bem como a formação profissional em nível superior em licenciatura, admitindo formação em nível médio na modalidade normal. (BRASIL, 1996)

Esforços legislativos no sentido de estabelecer padrões exigíveis de qualidade estão presentes no Parecer no 08/2010 do CNE/CEB (2010), que estabelece padrão mínimo de qualidade e piso salarial para os professores, melhoria da infraestrutura das escolas e garantia de número máximo de alunos por sala de aula; no PNE 2014-2024, com o estabelecimento do custo-aluno-qualidade (CAQ), que leva em consideração equidade e insumos, definem-se a especificidade da etapa da Educação Básica e do custo-aluno-qualidade inicial (CAQi). As iniciativas constantes da Meta 20 do PNE, que estabelecem o CAQi e do CAQ, revestem-se de grande importância na luta pela educação de qualidade, especialmente quando possuem potencial de elevar significativamente os gastos em educação.

O PNE (2014-2024), documento composto por metas e estratégias e que orienta ações nos planos estadual e municipal, reafirma algumas regras e princípios dos demais marcos legais em sua Meta 1, quais sejam: universalização do atendimento para a pré-escola e a ampliação da oferta em creches, colaboração entre os entes federados, levantamento e publicação dos dados sobre demanda para a Educação Infantil, respeito à diversidade, priorização do acesso à Educação Infantil, organização de ações voltadas ao aumento da taxa de frequência das crianças, estabelecimento de parcerias com demais órgãos públicos para buscar as crianças que não acessaram a escola, monitoramento de ações de acesso e permanência, garantia de atendimento em instituições a partir de parâmetros nacionais de qualidade, articulação da oferta em creches conveniadas com a expansão da oferta na rede direta ${ }^{2}$. Ainda mais: nas metas 5, 6 e 7 do Plano trata sobre o estímulo à qualidade por meio de procedimentos/instrumentos avaliativos. Na etapa em análise, a expansão voltou-se muito mais à quantidade do que à qualidade da oferta, especialmente pelo baixo custo que caracteriza o atendimento das crianças pobres, dada a contínua exclusão e desigualdade operada no interior dos sistemas de ensino (ROSEMBERG, 2002; SOARES, 2015) provocadas pela focalização das ações por políticas e programas de incentivo à expansão de outros arranjos educativos que conduzem a oferta desse nível de ensino a instituições conveniadas de caráter privado, mas financiadas com recursos públicos. 
O segundo relatório de monitoramento do PNE, de 2018, em série histórica de 2004 a $2016^{3}$, apresenta dados sobre a cobertura da Educação Infantil brasileira e o crescimento da desigualdade entre as áreas urbana e rural, negros e brancos, pobres e ricos (Tabela 1).

Tabela 1 - População na faixa etária de zero a três anos e de quatro a cinco anos que frequentava a escola no ano de 2016

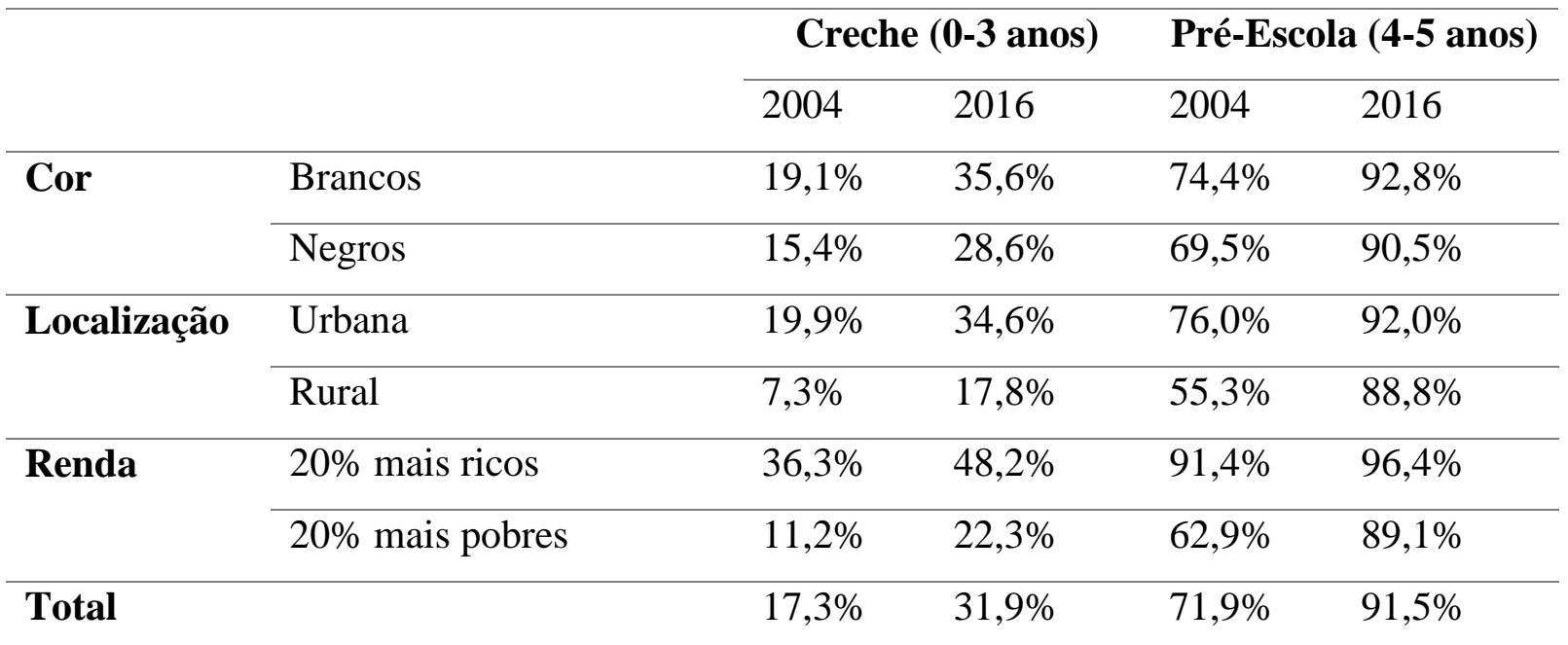

Fonte: Instituto Nacional de Estudos e Pesquisas Educacionais Anísio Teixeira (2019). Adaptado pelas autoras.

Os dados da Tabela 1 permitem afirmar que durante o período 2004-2015 a desigualdade cresceu, ao invés de diminuir, como preconiza a Estratégia 1.2 do PNE (2014): "garantir, que ao final da vigência deste PNE, seja inferior a $10 \%$ (dez por cento) a diferença entre as taxas de frequência à Educação Infantil das crianças de até 3 (três) anos oriundas do quinto de renda familiar per capita mais elevado e as do quinto de renda familiar per capita mais baixo." (PNE, 2014) O déficit da oferta é maior para os grupos mais vulneráveis, tanto em relação à renda quanto à cor e à localização de sua moradia. Tal fato é confirmado por pesquisa que indicou a maior proporção de crianças em piores condições de vida dentre aquelas que nunca frequentaram a pré-escola em comparação àquelas que já a haviam frequentado. (CAMPOS; COELHO; CRUZ, 2006)

A Estratégia 1.7, de "articular a oferta de matrículas gratuitas em creches certificadas como entidades beneficentes de assistência social na área de educação com a expansão da oferta na rede escolar pública" (BRASIL, 2014), veio a favorecer as políticas de realização de convênios com instituições privadas sem fins lucrativos e as formas alternativas de atendimento às crianças de 0 a 3 anos de idade, afetando diretamente as condições de acesso e a desigualdade, bem como as relações entre o público e o privado. Essa Estratégia tem sido objeto de polêmica em movimentos sociais, meios especializados, fóruns e conferências de educação. Os dados 
apresentados, a fim de demonstrar os desdobramentos dessa Estratégia no atendimento em creche, traz preocupações sobre a qualidade da etapa e também para a Estratégia 1.12, que possibilita diversos tipos de atendimento às crianças de 0 a 3 anos ao indicar que programas alternativos à creche devam ser implementados "em caráter complementar."

Mesmo após os avanços da CF (1988), foram incentivadas diversas soluções de emergência, tais como conveniamentos e oferta em espaços adaptados e com pessoal não qualificado, para resolver as requisições por vagas, ampliando as matrículas e minimizando os gastos públicos (CAMPOS; FULLGRAF; WIGGERS, 2006). De acordo com Bassi (2011, p. 122):

[...] diante do elevado custo de manutenção das creches públicas, não coberto pelo FUNDEB, e da obrigação legal à demanda crescente para a Educação Infantil, a tendência era que os municípios passassem a investir na expansão do conveniamento - menos oneroso para os cofres públicos, mas com a contrapartida de um atendimento precário.

Por meio do FUNDEB, há avanços na garantia do direito ao acesso de qualidade à educação, pois a questão do financiamento é fundamental para concretizar o direito à educação de qualidade. No entanto, os recursos ainda não são suficientes, na medida em que o montante gerado pela vinculação da receita municipal, FUNDEB, transferências e salário-educação, precisam de uma melhor e mais equitativa redistribuição entre os estados e municípios frente aos desafios postos à Educação Infantil de qualidade pelos contextos específicos dos entes federativos. (BASSI, 2011)

A tendência ao conveniamento na Educação Infantil é mais presente na faixa etária de 0 a 3 anos. Atualmente, o Brasil tem 69,7 mil creches, sendo 74,8\% delas na zona urbana. A maioria, 59,4\%, é municipal, e 40,4\%, privada, com $25 \%$ das creches privadas conveniadas com estados e/ou municípios. A Educação Infantil como um todo, considerando creche e pré-escola, atende 8,7 milhões de alunos (INEP, 2019). A ausência de prioridade ao atendimento educacional das crianças de zero a três anos engendra a construção de alternativas e possibilidades de conveniamento do poder público com instituições privadas, especialmente por meio das chamadas parcerias público-privadas, o que tende a trazer riscos para a qualidade do atendimento e para outros arranjos educativos, visto que não é uma etapa obrigatória.

Para além dos documentos destacados que apontam as condições de acesso, Toporosky (2017) e Ximenes (2014b) incorporam ao conceito de qualidade os seguintes princípios: participação na perspectiva democrática; autonomia das instituições, mas sem deixar de considerar a existência de parâmetros e indicadores para evitar as desigualdades; infraestrutura, 
espaços e insumos adequados, sejam nas condições materiais, recursos pedagógicos, condições de trabalho dos professores e relação adequada profissional/crianças; carreira docente com base nos art. 61 e 62 da LDB (1996), valorização profissional, piso salarial e incentivo à qualificação como elemento fundamental de qualidade da escola em geral; planejamento e proposta pedagógica, sob perspectiva democrática; rotina, linguagem e interação entre adultos e crianças, e avaliação na Educação Infantil ligada a proposta pedagógica de acordo com o desenvolvimento e necessidade das crianças e avaliação das situações conforme indicadores de qualidade nacionais. (TOPOROSKY, 2017; XIMENES, 2014b)

Ao nos aproximarmos da discussão aqui exposta, verificamos que diversos atores sociais, sobretudo aqueles ligados ao terceiro setor, disseminam proposições sobre a educação de qualidade que aliam esse conceito à oferta de vaga pública de Educação Infantil em estabelecimentos privados de ensino. Assim, no próximo item, buscaremos analisar quais essas intencionalidades do privado, por meio de documento exarado pela Fundação Maria Cecília Souto Vidigal (FMCSV).

\section{Qualidade da Educação Infantil e influência do privado: intencionalidades e encaminhamentos}

Os marcos legais apresentados na seção anterior indicam o poder público como principal promotor das políticas públicas de educação. Tal preceito é garantido pela Constituição Federal de 1988 ao estabelecer, em seu Artigo 205, a educação como direito de todos e dever do Estado e da família, a ser promovida e incentivada com a colaboração da sociedade. Ao longo dos anos 1990, essa "colaboração da sociedade" ganha relevo no âmbito das políticas educacionais, tanto no que se refere ao voluntariado quanto à colaboração entre os setores público e privado. Nessa perspectiva, o Estado se exime cada vez mais da execução das políticas públicas, mas permanece como indutor e avaliador (OSBORNE; GAEBLER, 1994). As ações implementadas nesse contexto pretendem visivelmente minimizar os investimentos em políticas sociais, como as de educação, e significam a apropriação dos fundos públicos por organizações privadas sob o argumento modernizador da desregulamentação e valorização da sociedade civil, liberandoa do que seria a tutela do Estado e, assim, favorecendo a privatização do atendimento público.

Ball e Youdell (2007) e Adrião et. al. (2015) nos ajudam a entender as principais formas de 'privatização acobertada' que ocorrem na educação pública: a privatização endógena e a privatização exógena, por essas formas constituindo-se os denominados quase-mercados educativos e as políticas de accountability. Identificam, ainda, a privatização da própria política, 
com a consolidação de atores do setor privado influenciando cada vez mais o debate e as próprias políticas educativas, além da venda de serviços, em detrimento dos mecanismos de participação democrática e do fortalecimento de atores comprometidos com a estruturação de sistemas públicos de educação (um dos princípios da qualidade anteriormente visto).

No Brasil, o Movimento Todos pela Educação (TPE) desponta como uma forte organização na defesa da incorporação de valores de mercado na educação pública como a eficiência, a eficácia e a qualidade entendidas como indicadores de bom rendimento e medidas em testes padronizados. Segundo Cossetin (2017), o TPE vem expandindo seu foco de atuação de modo que fundações e institutos atuem, de forma direta e indireta, nas diversas etapas da Educação Básica. Nesse universo, a Fundação Maria Cecília Souto Vidigal (FMCSV) vem se constituindo como instituição definidora e implementadora de políticas, programas e projetos que têm como público-alvo, como denominam, a primeira infância. Forte parceira do TPE, ela atua na produção de materiais didático-pedagógicos disseminadores de conhecimentos sobre desenvolvimento infantil, bem como orientações sobre como atingir uma Educação Infantil de qualidade.

A fim de identificar o conceito de qualidade defendido pela FMCV, foi realizada busca no sítio eletrônico da Fundação ${ }^{4}$, resultando na identificação do documento: "Educação Infantil em debate: a experiência de Portugal e a realidade brasileira", produzido pela própria FMCSV e pela Fundação Itaú Social em 2014, com o apoio do Fundo das Nações Unidas para a Infância (UNICEF) e coordenação técnica de pesquisadores do Centro de Criação de Imagem Popular (CECIP). O documento é dividido em oito capítulos que versam sobre: organização da gestão, fontes de financiamento, formação e identidade profissional, estruturação do currículo, sistema de avaliação, participação da sociedade civil, expansão da cobertura e experiência portuguesa e sua contribuição para o Brasil, sobretudo no segmento creche, no qual a oferta brasileira não é obrigatória, mas é um direito fundamental subjetivo.

Apesar da manifesta intenção de não utilizar a organização da Educação Infantil em Portugal como modelo para o Brasil, pois "O Brasil não precisa de modelos, mas de interlocutores" (FMCSV; FUNDAÇÃO ITAÚ SOCIAL, 2014, p. 7), o modelo daquele país parece apontar tendências profícuas e tem sido assimilado no Brasil por meio das organizações do terceiro setor. Uma dessas tendências está no distanciamento entre a Educação Infantil e o Ministério da Educação em Portugal, cuja oferta possui clara vinculação com parcerias públicoprivadas de caráter filantrópico, como evidencia o excerto a seguir: “[...] maioria das creches 
portuguesas permanece sob a tutela de organizações filantrópicas, que operam serviços de assistência social." (op.cit., p. 22). Ao tratar de Portugal, asseveram:

\begin{abstract}
Por um lado, reconhecem que, de certo modo, a prática afasta as instituições filantrópicas de seu objetivo maior, que é o de servir aos mais pobres. Por outro lado, entendem que a estratégia contribui para garantir mais qualidade nas creches e préescolas: ao ter de atrair um público de maior poder aquisitivo - e possivelmente com maior nível de escolaridade e de acesso à informação - as instituições precisam se esmerar para manter um padrão de excelência, não só em termos de estrutura física e equipamentos, mas também de conteúdo pedagógico. Além disso, a convivência de crianças de diferentes classes sociais, com diferentes experiências de vida, culturas, religião e muitas vezes até falando línguas variadas, traz benefícios pedagógicos a todas. (op.cit., p. 31)
\end{abstract}

O modelo de financiamento do governo de Portugal a creches e pré-escolas filantrópicas, para ser viável, requer que essas instituições atraiam certo número de famílias de classes média e alta. As mensalidades mais altas pagas por esse público de maior poder aquisitivo são necessárias para compensar as mensalidades deficitárias pagas pela população de menor renda. Assim, a família é a principal responsável e o Estado apoia a educação da criança. Desse modo, o Estado não tem o dever de oferecer estabelecimentos para o atendimento educativo das crianças nessa faixa etária, cabendo a ele apoiar as famílias que não tenham um adulto que possa cuidar da criança em casa por meio de oferta de vaga em creche, a fim de acolher seus filhos nos períodos em que os responsáveis estiverem trabalhando. Assim, o apoio do Estado se destina ao atendimento nessas creches e a outras formas de atendimento direto às crianças de zero a três anos, por meio do repasse de recursos para organizações filantrópicas pelo Ministério da Solidariedade e da Segurança Social (MSSS), e não o Ministério da Educação, a partir de componentes educativos e não do trabalho educativo.

Outra dimensão apontada é a qualidade da formação profissional. Segundo o estudo em questão, em Portugal os educadores de infância são responsáveis pelo projeto educativo e pedagógico da creche e, com os ajudantes de ação educativa, desenvolvem atividades sóciopedagógicas e de cuidado com crianças a partir de um ano. No berçário, a lei não requer a presença de um educador de infância no trabalho direto com os bebês, trabalho que é realizado pelos técnicos da área do desenvolvimento infantil ou pelos ajudantes de ação educativa, sob supervisão dos educadores de infância. Ou seja, a formação para atuar com a primeira etapa da Educação Infantil não requer profissionais com formação adequada, juntamente àquela oferta em instituições filantrópicas, creches comunitárias e $\mathrm{Amas}^{5}$. O documento enfatiza que, para a atingir educação infantil de qualidade, "Conhecer a realidade de Portugal, [...] pode iluminar a nossa própria situação, tornando mais claros os desafios brasileiros nessa área." (FMCSV; FUNDAÇÃO ITAÚ SOCIAL, 2014, p. 71, grifos nossos). Ao analisar a pesquisa realizada, é 
visível a intencionalidade de demarcar que essas possibilidades poderiam ser exploradas no Brasil, a partir da consolidação de parcerias público-privadas.

Tais parcerias são incentivadas pelas agências internacionais desde a década de 1990, como evidencia Robertson (2012), unindo diferentes atores e setores sociais em torno da “...corretagem ['broker in'], em vez de mitigação ou mediação da privatização na e da educação.” (ROBERTSON, 2012, p. 290) Com a crise econômica de 2008, essa ideia retorna com força, manifestando-se como eixo fundamental no documento Estratégia 2020 para a educação do Banco Mundial, divulgado em abril de 2011 pelo Novo Grupo Banco Mundial. Esse documento, segundo a autora, “...redefine o sentido de um sistema de educação para que agora inclua, e anexe, o setor privado (lucrativo ou não) como ator-chave por dentro, e não por fora, do sistema de educação.” (op..cit., p. 295) O documento, que pretende redefinir os valores e orientações de um ‘Novo' Grupo Banco Mundial, a partir da crise econômica de 2008, parece reconhecer os limites do mercado como modelo para o desenvolvimento da educação. Entretanto, como afirma Robertson (2012, p. 294), "também promove implicitamente a percepção de que o Estado fornece uma rede de segurança para aqueles com recursos insuficientes para participar do setor privado.” (op.cit., p. 294)

Nessa direção, o documento da FMCSV, embora afirme o papel do Estado na garantia do acesso, sustenta que a oferta pode ser realizada tanto pelo sistema público quanto pelo filantrópico, havendo ainda a possibilidade de repasse, em número reduzido, de recursos para organizações privadas com fins lucrativos, caso não haja vagas públicas ou filantrópicas (FMCSV; FUNDAÇÃO ITAÚ SOCIAL; 2014). Rosemberg (2002) ajuda-nos a compreender esse cenário ao afirmar que, no Brasil, para reduzir os investimentos públicos, desenvolvem-se políticas e programas - denominados 'não formais', 'alternativos', 'não institucionais' - que se apoiam nos recursos da comunidade, isto é, espaços, materiais, equipamentos e recursos humanos disponíveis na comunidade, ainda que faltem conhecimentos e materiais pedagógicos profissionais e não haja compromisso com objetivos e intencionalidades claros.

Essas são algumas das intencionalidades das propostas desenvolvidas em Portugal que poderiam ser seguidas no Brasil, de acordo com a perspectiva da FMCSV e da Fundação Itaú Social. Todavia, chamamos atenção para as considerações de Rosemberg (2002), que critica não apenas o caráter informal dos programas e seu pretenso baixo custo, mas principalmente o fato de configurar-se como programas incompletos, emergenciais e focalizados que acabam por se estender ao longo do tempo, o que resulta, constantemente, em atendimento de pouca efetividade e muita instabilidade. (ADRIÃO, et. al., 2015) 
A pesquisa realizada pela FMCSV e Fundação Itaú Social é reveladora quanto a demarcar as intencionalidades engendradas por meio do terceiro setor e que incidem na Educação Básica pública. Essas intencionalidades convergem não com a preocupação com a qualidade do atendimento educativo que será oferecido nem com o nível de formação dos que estiverem envolvidos em sua consecução, mas com os enunciados de implementação das parcerias público-privadas para a oferta das políticas sociais focalizadas, contrapondo-se a toda discussão levantada sobre a maximização do conceito de qualidade do direito à Educação Infantil que recentemente se buscou garantir nos documentos nacionais.

Ao analisarmos o estudo produzido pela FMCSV e pela Fundação Itaú Social, Educação Infantil em debate: a experiência de Portugal e a realidade brasileira, observamos sua convergência com o documento Educação Infantil: Programas para a geração mais importante do Brasil (EVANS; KOSEC, 2011) e com a Declaração de Incheon (UNESCO, 2015), no sentido de atrelar a educação ao crescimento econômico e focalizar a oferta da Educação Infantil para os mais pobres, e, sobretudo, no que se refere ao indicativo das parceiras, tanto para a oferta da Educação Infantil, principalmente para o segmento de 0 a 3 anos, quanto para outros programas que atenderiam à infância, já que não se propõe a universalidade das políticas.

Compreendemos que a atuação do terceiro setor não se dá, meramente, pela execução direta das atividades, mas também ocorre pela abertura de espaços na definição das políticas que são implementadas. Desse modo, um dos passos na direção de constituição de parcerias e de sua consolidação por meio de legislações específicas ocorre com a abertura da interlocução privilegiada oferecida e pela disseminação de documentos como o analisado.

As tendências na produção de intencionalidades a partir de uma lógica privada na educação pública e a incidência dos atores empresariais na gestão da política educacional, em detrimento dos mecanismos de participação democrática e do fortalecimento de atores comprometidos profissionalmente, enfraquece a estruturação de sistemas públicos de educação de qualidade. Aferimos, assim, que as intencionalidades da endoprivatização na Educação Infantil seguem, tendencialmente, à exoprivatização (BALL; YOUDELL, 2007), alinhadas, ainda, às orientações dos organismos multilaterais. Essas ações estão, direta e indiretamente, relacionadas à procura e criação de novas oportunidades de lucro.

\section{Considerações finais}

À guisa de conclusão, afirmamos que a garantia deve ser buscada da forma mais ampla e maximizada possível, e que o primeiro desafio se vence pelo acesso. Entretanto, grupos 
empresariais estão envolvidos nas discussões sobre educação, envolvimento esse que não se dá, meramente, pela execução direta das atividades de atendimento à educação, mas que se consolida com a abertura da interlocução privilegiada oferecida, não a todos, favorecendo mais decisivamente a grupos que representam as elites, como o empresariado.

Tais grupos vêm atuando de forma endógena e exógena nos sistemas de ensino, nos debates públicos, na positivação de leis, na produção de material. Ademais, tal atuação aponta para uma Educação Infantil de qualidade que se vincula a noções de eficiência e eficácia no plano de uma relação custo-benefício medida quase exclusivamente pela monetização do serviço público, pautada numa organização de oferta que converge não pela preocupação com a maximização da qualidade do atendimento educativo que será oferecido, mas com os enunciados de implementação das parcerias público-privadas para a oferta de políticas sociais focalizadas e, consequentemente, precarizadas.

Se o direito à educação de qualidade "visa primariamente proteger a máxima qualidade do ensino" (XIMENES, 2014b, p. 121), não há dúvidas de que as intencionalidades do privado não corroboram para essa conceituação: elas se contrapõem, politicamente, a toda a discussão contemporânea de maximização do conceito de qualidade do direito à Educação Infantil. É fundamental fortalecer a luta pela maximização do direito à qualidade pautada na democracia, no pluralismo e na justiça, ajustados tais princípios aos mutáveis e diversos contextos socioculturais nos quais estiver inserida. Esse fortalecimento requer como condições sine qua non, ainda que não únicas, a valorização dos sujeitos da comunidade educativa, a importância do desenvolvimento pleno das crianças, a gestão democrática e um financiamento público condizente com a plena garantia do direito à qualidade.

\footnotetext{
${ }^{1}$ Considerar a educação como direito público subjetivo, plenamente exigível e acionável, se dá pela necessidade do Estado de fornecê-la conforme estabelece a Carta Magna brasileira de 1988. A ausência de observância do direito pelo administrador, com a possibilidade de requisitar seu cumprimento em juízo, indica o exercício do direito público subjetivo (DUARTE, 2004). Lopes (2002) defende, ainda, que a inexistência de meios que possibilitem ao indivíduo exigir seu cumprimento acaba por retirar da previsão sua própria característica de direito.

2 É preciso considerar a precariedade das instituições conveniadas, evidenciada em vários estudos. Como argumenta Nunes (2011, p. 12): “O conveniamento não está articulado à qualidade da educação. Pelo contrário, a história dos convênios responde à falta de oferta de vagas em creches e pré-escolas públicas e a uma concepção de que, para a classe trabalhadora, qualquer tipo de atendimento seria suficiente."

${ }^{3}$ Indicadores utilizam os microdados da Pesquisa Nacional por Amostra de Domicílios (Pnad) anual, realizada pelo Instituto Brasileiro de Geografia e Estatística (IBGE); e para o ano de 2016, os microdados da Pnad contínua (Pnad-c/ IBGE). A estimativa para o ano de 2016 é apresentada em continuidade à série histórica 2004-2015.

${ }^{4}$ http://www.fmcsv.org.br/pt-br/acervo-digital/Paginas/default.aspx?PalavraChave=qualidade, acesso em 23 de julho de 2018.
} 


\footnotetext{
5 As Amas portuguesas, conforme sugestão das Fundações, referem-se a pessoa que, mediante pagamento, cuida em sua residência de crianças de até três anos de idade ou até atingir a idade de ingresso nos estabelecimentos de educação préescolar, por um período de tempo correspondente ao trabalho ou impedimento da família.
}

\section{Referências}

ADRIÃO, Theresa; GARCIA, Teise; BORGHI, Raquel; BERTAGNA, Regiane; PAIVA, Gustavo; XIMENES, Salomão. Sistemas de Ensino Privado na Educação Pública Brasileira: consequências da mercantilização para o direito à educação. Relatório de Pesquisa. GREPPE, Ação Educativa. 2015. Disponível em:

http://acaoeducativa.org.br/wpcontent/uploads/2016/10/sistemas_privados_pt.pdf. Acesso em 24 de julho de 2018.

AFONSO, Almerindo Janela. Avaliação educacional - regulação e emancipação. 4 ed. São Paulo: Cortez, 2009.

ALEXY, Robert. Teoria dos direitos fundamentais. 5 ed. (Tradução de: Virgílio Afonso da Silva). São Paulo: Malheiros, 2015.

ALVES, Giovanni. Trabalho e mundialização do capital. São Paulo: Editora Práxis, 1999. BALL, S.; MAINARDES, J. (org.). Políticas educacionais: questões e dilemas. São Paulo: Cortez, 2011. p. 222-248.

BALL, Stephan; YODELL, Debora. Privatización encubierta en la educación pública, Internacional de la Educación, V Congreso Mundial. 2007. Disponível em:

http://www.joanmayans.com/privatizacion_encubierta_de_la_educacion_publica.pdf. Acesso em: 24 de junho de 2018.

BASSI, Marcos Edgar. Financiamento da Educação Infantil em seis capitais brasileiras. Cadernos de Pesquisa, São Paulo, v. 41, n. 142, jan. /abr. 2011. p. 116-141.

BEISIEGEL, Celso de Rui. A qualidade do ensino na escola pública. Brasília: Liber Livro, 2006.

BRASIL. Conselho Nacional de Educação (CNE). Câmara de Educação Básica (CEB). Parecer CNE/CEB $n^{\circ}$ 8, aprovado em 5 de maio de 2010. Estabelece normas para aplicação do inciso IX do artigo 4o da Lei no 9.394/96 (LDB), que trata dos padrões mínimos de qualidade de ensino para a Educação Básica pública. 2010.

BRASIL. Constituição da República Federativa do Brasil. Brasília, Congresso Nacional, 5 out. 1988.

BRASIL. Emenda Constitucional $n^{\circ} 59$, de 11 de novembro de 2009 . Acrescenta $\S 3^{\circ}$ ao art. 76 do Ato das Disposições Constitucionais Transitórias para reduzir, anualmente, a partir do exercício de 2009, o percentual da Desvinculação das Receitas da União incidente sobre os recursos destinados à manutenção e desenvolvimento do ensino de que trata 0 art. 212 da Constituição Federal, dá nova redação aos incisos I e VII do art. 208, de forma a prever a obrigatoriedade do ensino de quatro a dezessete anos e ampliar a abrangência dos programas suplementares para todas as etapas da educação básica, e dá nova redação ao $\S 4^{\circ}$ do art. 211 e 
ao $\S 3^{\circ}$ do art. 212 e ao caput do art. 214, com a inserção neste dispositivo de inciso VI.. Brasília, 12 nov. 2009. Disponível em:

http://www.planalto.gov.br/ccivil_03/constituicao/emendas/emc/emc59.htm. Acesso em: 22 jan. 2019.

BRASIL. Lei Federal 9.394. Estabelece as diretrizes e bases da educação nacional. Brasília: Congresso Nacional, 23 dez. 1996.

BRASIL. Lei n. 12.796, de 4 de abril de 2013: altera a Lei n. 9.394 de 20 de dezembro de 1996, que estabelece as diretrizes e bases da educação nacional, para dispor sobre a formação dos profissionais da educação e dar outras providências. Brasília: Congresso Nacional, 2013.

BRASIL. Lei $n^{\circ} 13.005$, de 25 de junho de 2014. Aprova o Plano Nacional de Educação PNE e dá outras providências. Brasília: Congresso Nacional, 2014.

CAMPOS, Maria Malta; COELHO, Rita de Cássia; CRUZ, Silvia H. Vieira. Consulta sobre qualidade da Educação Infantil: relatório técnico final. São Paulo: FCC/DPE,

CAMPOS, Maria Malta; HADDAD, Sérgio. O direito humano à educação escolar pública de qualidade. In HADDAD, Sérgio; GRACIANO, Mariângela. A educação entre os direitos humanos. Campinas: Autores Associados, 2006. P. 95-125.

COSSETIN, Márcia. As políticas educacionais no Brasil e o Movimento Todos pela

Educação: parcerias público-privadas e as intencionalidades para a educação infantil. $337 \mathrm{f}$. Tese (Doutorado em Educação) - Universidade Estadual de Maringá, Maringá, 2017.

CURY, Carlos Roberto Jamil. A qualidade da educação brasileira como direito. Educação e Sociedade, Campinas, v. 35, n. 129, p.1053-1066, out. 2014. Trimestral. Disponível em: 〈http://www.scielo.br/scielo.php?pid=S0101-

73302014000401053\&script=sci_abstract\&tlng=es $>$. Acesso em: 09 nov. 2018

DUARTE, Clarice Seixas. Direito público subjetivo e políticas educacionais. São Paulo em Perspectiva. São Paulo, v. 18, n. 2, 2004. p. 113-118.

EVANS, David K.; KOSEC, Katrina. Educação Infantil: Programas para a geração mais importante do Brasil. São Paulo: Editor: Ex-Libris Comunicação Integrada, Tradução para o português: Fundação Maria Cecília Souto Vidigal, 15 de jun. de 2011.

FMCSV; FUNDAÇÃO ITAÚ SOCIAL. Educação Infantil em debate: a experiência de Portugal e a realidade brasileira. São Paulo: Fundação Itaú Social; Fundação Maria Cecília Souto Vidigal, 2014.

INEP. DADOS DO CENSO ESCOLAR - Número de matrículas na Educação Infantil cresceu 11,1\% de 2014 a 2018. 2019. Disponível em: http://portal.inep.gov.br/artigo//asset_publisher/B4AQV9zFY7Bv/content/dados-do-censo-escolar-numero-de-matriculas-naeducacao-infantil-cresceu-11-1-de-2014-a-2018/21206. Acesso em: 20 de fevereiro de 2019.

GROSO, Camilla; MAGALHÃES, Giovanna Modé. Privatização da Educação América Latina e no Caribe: tendências e riscos para os sistemas públicos de ensino. Educação e Sociedade, v. 37, n 134, p. 17-33, jan-mar., 2016. 
INEP. $2^{\circ}$ Ciclo de Monitoramento das Metas do Plano Nacional de Educação - 2018. Brasília, DF: Inep, 2018.

KRAWCZYK, Nora Rut. O ensino médio no Brasil. São Paulo: Ação Educativa, 2009.

LOPES, José Reinaldo de Lima. Direito subjetivo e direitos sociais: o dilema do judiciário no estado social de direito. In: FARIA, José Eduardo (Org.). Direitos Humanos, Direitos Sociais e Justiça. São Paulo: Malheiros Editores, 2002.

NUNES, Deise Gonçalves. Expandir vagas por meio de convênios com creches privadas pode ser um grave retrocesso no PNE. Observatório da Educação: Ação Educativa. 2011. Disponível em: <http://www.observatoriodaeducacao.org.br/index.php/entrevistas/56entrevistas/1127-expandir-vagas-pormeio-de-convenio-com-creches-privadas-pode-ser-umgrave-retrocessono-pne-afirma-pesquisadora-da-uff $>$. Entrevista concedida em 19 de dezembro de 2011.Acesso em: 21 de janeiro de 2019.

OLIVEIRA, Romualdo Portela de; ARAÚJO, Gilda C. Qualidade do Ensino: uma nova dimensão da luta pelo direito à educação. Revista Brasileira de Educação, (28), jan-abr, 2005. p. 5-23.

OSBORNE, David; GAEBLER, Ted. Reinventando o governo: como o espírito empreendedor está transformando o setor público. Brasília: MH Comunicação, 1994.

PERONI, Vera Maria; OLIVEIRA, Regina Tereza Cestari de; FERNANDES, Maria Dilnéia. Estado e Terceiro Setor: As novas Regulações entre o Público e o Privado na Gestão da Educação Básica Brasileira. Educação e Sociedade, Campinas, vol. 30, n. 108, out. 2009. p. 761-778.

PINTO, José Marcelino Resende. A política recente de fundos para o financiamento da educação e seus efeitos no pacto federativo. Educação e Sociedade, Campinas, v. 28, n. 100, out. 2007. p. 877-897.

ROBERTSON, Susan L. A estranha não morte da privatização neoliberal na Estratégia 2020 para a educação do Banco Mundial. Revista Brasileira de Educação, v. 17 n. 50 maio-ago. 2012.

ROSEMBERG, Fúlvia. Organizações multilaterais, Estado e políticas de Educação Infantil. Cadernos de Pesquisa, n. 115, março, 2002. p. 25-63.

ROSEMBERG, Fúlvia. São Paulo, uma cidade hostil aos bebês. In: ARTES, Amélia; UNBEHAUM, Sandra. Escritos de Fúlvia Rosemberg. Cortez: São Paulo, 2015. p. 210-215.

SHIROMA, Eneida Oto; CAMPOS, Rolenane Fátima; GARCIA, Rosalba Maria Cardoso. Conversão das "almas" pela liturgia da palavra: uma análise do discurso do movimento Todos pela Educação. In: BALL; Stephen; MAINARDES, Jefferson. (Org.). Políticas Educacionais: questões e dilemas. 1 ed. São Paulo: Cortez, 2011, v. 1. p. 174-197. 
TAPOROSKY, Barbara Cristina Hanauer. O controle judicial da qualidade da oferta da Educação Infantil: um estudo das ações coletivas nos tribunais de justiça do Brasil (20052016). Dissertação de Mestrado. Universidade Federal do Paraná. Curitiba, 2017. 202 f.

TOMASEVISK, Katatina. Human Rights obligations: making education avaliable, accesible, aceptable and adaptable. Right to Education $n^{\circ}$ 3. SIDA; Raoul Wallenberg Institute of Human Rights and Humanitarian Law: Gothemburg, 2001.

UNESCO. Educação 2030 Declaração de Incheon rumo a uma educação de qualidade inclusiva e equitativa e à educação ao longo da vida para todos. 2015. Disponível em: http://unesdoc.unesco.org/images/0023/002331/233137POR.pdf. Acesso em: 9 jan. 2019.

XIMENES, Salomão Barros. O Conteúdo Jurídico do Princípio Constitucional da Garantia de Padrão de Qualidade do Ensino: uma contribuição desde a teoria dos direitos fundamentais. Educ. Soc., [s.1.], v. 35, n. 129, dez. 2014a. p.1027-1051.

XIMENES, Salomão De Barros. Direito à qualidade na educação básica: teoria e crítica. São Paulo: QuartierLatin, 2014b. 